\title{
Administrative Corruption and Taxation
}

\author{
FRANK FLATTERS \\ Department of Economics, Queen's University, Kingston, Ontario, Canada, K7L 3N6 \\ W. BENTLEY MACLEOD \\ Université de Montréal, C.R.D.E, C.P. 6128, succursale A, Montréal, Québec, Canada, H3C 3J7
}

\begin{abstract}
Administrative corruption, whereby taxpayers and collectors collude to reduce remissions, is central to tax evasion in developing countries. A framework is developed for the analysis of such corruption, based on imperfect information concerning true tax liabilities. Some tolerance of corruption can be part of an efficient collection system, especially when there are constraints on government wages and/or effort is required to learn payers' tax liabilities. With variable collector effort a certain amount of corruption is required, together with a two level penalty structure dismissal if revenue targets are not met, and much heavier penalties for gross corruption.
\end{abstract}

Key words: corruption, development, taxes

\section{Introduction}

Wherever taxes are levied, there are agents who will try to avoid or evade them. In many developing countries, however, large-scale tax evasion is systemic. Economists (such as Allingham and Sandmo, 1972; Cowell, 1990; Usher, 1986; Yitzathki, 1987) have recognized the importance of this behavior in the design of optimal tax systems, and have paid increasing attention to the analysis of schemes for detecting and modifying such behavior (see, for example, Cremer, Marchand and Pestieau, 1988; Graetz, Reinganum and Wilde, 1986; Reinganum and Wilde, 1985; and Toma and Toma, 1992). Almost all of this literature, however, fails to take account of the role of dishonest tax collectors, thus ignoring the important phenomenon of administrative corruption, whereby taxpayers and tax collectors collude to avoid the payment of 
legal tax liabilities to the government. ${ }^{1}$ The purpose of this paper is to provide a simple framework for the analysis of such corruption, with special attention to some of the important features of the administration of developing country tax systems.

In discussions of customs enforcement in developing countries, one often hears of the distinction between physical smuggling and administrative smuggling. The former, in which the importer simply avoids dealing with the customs officer altogether, corresponds to the sort of evasion that is modeled in the traditional tax evasion literature. It is the latter, often much more prevalent, type of tax evasion, in which the taxpayers and the tax collectors collude, which is the subject of this paper. In order to avoid unnecessary complications, we simply rule out any form of tax evasion in which the tax collectors do not participate.

The principal problem we address is the design of incentive systems to ensure that tax collectors perform their job at the least social cost. Is it possible to design an incentive scheme that would eliminate all administrative corruption? Is it desirable in all circumstances to attempt to minimize the scope of such corruption? In other words, is corruption always an example of wasteful rent-seeking behavior, or are there circumstances in which it might be an efficiencyenhancing response to administrative or other constraints? What possible role might corruption play in the design of systems of taxation and other types of economic regulation?

Administrative corruption in the tax system arises for two reasons. First, in order to determine taxpayers' true tax liabilities, it is necessary for the government to delegate authority to tax officials who have the ability to obtain the information necessary to make this determination. Second, the government has imperfect ability to monitor the behavior of its tax officials. This problem arises everywhere, but is more serious in developing countries with poorly developed accounting and bookkeeping standards. Customs officers, for instance, are required to determine the classification and the values of imported goods. Income tax agents have to assess the "true" income of taxpayers and, in cases where rates differ according to income source, the proper classification of various income components. The basis for these determinations is generally much weaker than in more developed countries, as is the ability of the government to ascertain whether tax officials are making correct assessments and collecting the payments that correspond to the taxpayers' true tax liabilities.

This gives rise to opportunities for collusion between collectors and taxpayers to reduce 
the latter's tax liabilities. The methods are many: customs officers misclassify imports into lower rate or less restricted categories; they undervalue shipments by understating their volumes or their market values; they turn a blind eye while goods are removed from customs warehouses without proper customs entries and hence without payment of duties. Similarly, income tax officials agree to overlook certain sources of income or to permit overstatement of various sorts of expenses incurred to earn it. In return for reductions in tax payments, the tax officials receive (often sizeable) bribes from the taxpayers.

This sort of corruption manifests itself in developing countries in a number of standard ways: there is considerable underpayment of taxes; tax revenue agents, despite low official incomes, are able to accumulate significant amounts of wealth while in office; and potential tax agents are often willing to make sizeable side-payments to secure employment in the revenue department.

Despite such widespread and widely acknowledged corruption, prosecutions of corrupt revenue agents are rare, and penalties are seldom more severe than job dismissal. Delinquent taxpayers are practically never prosecuted. And yet one occasionally runs across a sensational case in which an official is not only fired, but also penalized with heavy fines and a long jail sentence for what seems to be the same sort of corrupt behavior. In other words, administrative corruption is systemic, and efforts to reduce it are erratic at best. Why is pervasive and widely known corruption tolerated? Why are the penalties for corrupt behavior so small and so infrequently imposed? And why are there occasional high profile prosecutions, in which much heavier penalties are imposed for the same kind of behavior?

Our purpose is to build some simple models to shed light on these sorts of phenomena. The two most important analytical issues are the sharing of the rents between the taxpayers and the tax officials, and the design of an efficient incentive system for the tax officials. We solve the first problem by utilizing a solution concept from the theory of cooperative games. This gives us a well-defined sharing rule in which the rents are divided according to the relative powers of the two sets of agents in this collaboration - the taxpayers and tax collectors.

The incentive question is embedded in a framework in which the government chooses both a wage for tax officials, and a degree of latitude for corruption that is based on the slack 
between aggregate legal tax liabilities and the revenue targets given to the tax officials. These incentives are set at a level that is sufficient to ensure that the tax officials meet the government's revenue target. In the most basic model, wages and bribes are perfect substitutes in providing incentives for tax collectors. Corruption is not necessary, but it is not harmful. However, in the presence of constraints on civil service wages, such as civil service wage ceilings or wage parity between the tax office and other government departments, some latitude for corruption becomes a necessary part of the incentive structure.

When the model is modified to require effort on the part of the tax collectors to determine individuals' tax liabilities, corruption, in the form of "permission" to collect side payments from

taxpayers, becomes a necessary part of the efficient reward system. ${ }^{2}$ With variable tax collector effort, we find as well that a two-level penalty structure is most efficient. A certain amount of corruption is condoned in order to induce work effort. The ultimate penalty for laziness is job dismissal for the tax collector. In addition, however, in order to prevent gross levels of corruption, such as failing to remit any tax collections, a second, much more severe sanction, such as a long jail term or heavy financial penalty, is necessary. Job dismissal alone would require much higher levels of tax collector wages or bribery, and thus impose very heavy costs on the tax collection system.

The models are normative in nature - that is, they discuss optimal incentive mechanisms for tax officials in various circumstances with imperfect monitoring. However, we argue that the models, and especially the final one, provide reasonable predictions about some features of tax design and administrative corruption in developing countries. They certainly help to resolve some of the puzzles presented above. And some of the obvious policy implications accord with recent tax reform experiences in such countries.

The next section provides a general outline of the model. The subsequent one analyzes the division of the surplus from corruption between the taxpayers and tax officials. These results are then used to focus on the design of optimal incentive systems for tax officials to minimize the social cost of tax collection.

\section{General Description of the Model}

There are three types of agents in the model. The first is the Minister of Finance (or 
government, or president), who wishes to raise tax revenues for unspecified public purposes. The Minister specifies revenue targets, sets the parameters of the tax system, ${ }^{3}$ and chooses the wages of tax collectors. The second type of agent is the Collector, who is appointed by the Minister to administer the tax laws and collect tax revenues. It is the Collector who has or is able, with some effort, to obtain the information necessary to determine individual taxpayers' tax liabilities. The Collector is paid a wage, $w$, which, together with some possible scope for bribe-taking is the reward for delivering revenues to the Minister. Finally, the Payers pay taxes to the Collector.

The tax collection process, including the setting of the Collector's wage, is viewed as a simple game. The Minister sets an overall revenue target, $R$, in light of the government's expenditure needs. The expenditure needs comprise exogenous expenditures, $G$, and the (endogenous) wages, $w$, that are paid to the Collector. In other words, $R=G+w$. The Minister also specifies a tax system which determines the legal tax liability, $L(i)$, of each Payer, $i$. This liability depends on characteristics of the Payer that are unknown to the Minister. However, it is possible that the Minister has enough information to determine some minimum tax liability of Payers, $\underline{L}(i))$. Furthermore, the Minister has insufficient information and/or resources to monitor the day-to-day activities (especially revenue collections) of the Collector. The Collector, as already mentioned, is able to determine the precise legal tax liabilities of each Payer. Each Payer knows his or her own tax liability, and is always free simply to remit this amount to the government.

The Minister's problem is to choose an incentive scheme for the Collector to ensure that at least $R$ is raised from the Payers and remitted to the government. The goal in choosing the incentive scheme is to minimize overall collection costs. If the total legal tax liabilities of the Payers, $L$, exceed the revenue target, $R$, then there is room for mutually beneficial collusion between the Payers and the Collector. Rather than remitting his or her true tax liability, any Payer has the alternative of making a deal with the Collector to remit a smaller amount, with the Collector in turn remitting a still lesser amount to the Minister. The Payer and the Collector both gain, and the Minister can still meet the preset revenue target. The Minister's decision concerns the extent to which to reimburse the Collector through official wages, $w$, or by providing scope for bribe-taking by allowing some slack between $L$ and $R$. 
Our model differs in number of ways from that of Besley and McLaren (1993). In their model there are both "honest" and "dishonest" collectors, and the mix varies over time as a result of natural turnover and dismissals. Nothing in our model relies on differences in preferences for "honesty" among collectors. In Besley and McLaren, taxpayers never remit unless they happen to encounter an honest tax collector, and dishonest collectors never submit any revenues unless they are caught (and fired) by an auditor. In our model, the revenue target ensures that, under the incentive schemes we derive, (dishonest) collectors make remissions to the government. Finally, Besley and McLaren's "efficiency wage" is one that eliminates all corruption; our "efficiency wage" (although we don't call it that) is one that minimizes the social cost of tax collection. While the Besley and McLaren framework is useful for capturing some interesting issues with respect to the evolving composition of the set of tax collectors, we would argue that some of their basic assumptions do not accord with our observation of the way corruption occurs in tax administration in many developing countries. We do not deal with the problem, raised in Besley and McLaren's appendix and in Basu, Bhattacharya, and Mishra (1992), of the control of the auditors.

As mentioned earlier, the primary purpose of the paper is to examine the properties of incentive systems that ensure that Collectors perform their job at the least social cost, and what role corruption might play in the design of administrative systems for tax collection.

The first step in addressing this incentive design problem is to model the division of the "corruption surplus" among the Payers and the Collector. It is to this issue that we turn in the next section.

\section{Division of the Surplus}

The division of the surplus from administrative corruption can be thought of as a cooperative game among the Payers and the Collector. The issue we face is that of dividing the potential gains from cooperation between the tax collector and a large number of taxpayers. We would like to have a rule that reflects the maximum tax liabilities of each payer and the fact that the tax collector is an essential party in the corruption process. It should be pointed out that this cannot be solved as a simple bargaining problem between a single taxpayer and the tax collector. This is because there exists an aggregate revenue target, and therefore the current surplus 
available to be shared between the Collector and a Payer depends on the taxes that have already been collected elsewhere.

In this paper we use a simple solution to this problem - namely, the Shapley value. This solution concept defines the payoff to each person in a multiperson game as a function of their marginal contributions to the total surplus (see Moulin, 1988, for an excellent overview). We could have defined a noncooperative game, as in Gul (1989). However, this would have greatly complicated the analysis without offering a more convincing approach. The outcome predicted by the Nash equilibrium of an extensive form game is very sensitive to the way we define the extensive form. Furthermore, the extensive form is never observed in practice, and therefore its choice is necessarily arbitrary. The Shapley value has the attractive feature of ignoring the details of the strategic game and defining the payoffs only in terms of observable actions. Therefore, it is much more amenable to being confronted with the data.

The Shapley value is the unique division of the total surplus that satisfies the following conditions:

- Individuals are treated symmetrically. That is, their identities are irrelevant; it is only the way they are able to affect payoffs that matters.

- The value is additive. That is, if two different situations or games are combined, the payoff to an individual is equal to the sum of his/her payoffs from each game.

It can also be shown that the Shapley value allocation to each individual is an amount equal to the expected marginal contribution of that individual in a randomly chosen coalition. This potential marginal contribution can be interpreted in terms of each coalition member's relative power in the group. The power of the Collector in this particular surplus division game derives from his or her ability to effect a reduction in tax liabilities. The power of the Payers derives from their ability to pay their full tax liabilities and deprive the Collector of supplementary income in the form of bribes.

Formally, the Shapley value gives each agent his or her marginal contribution to the surplus when coalitions are formed in a random fashion. For our purposes, we need only determine the total bribe the Collector receives. This requires finding the expected contribution of the Collector to an arbitrary coalition of taxpayers. Suppose that a coalition consisting of a 
fraction, $n$, of the taxpayers forms. In the absence of cooperation by the Collector, they must pay an amount $n L$ in tax liabilities. If they form a coalition with the Collector, then the remaining tax payers are assumed to pay their full tax liabilities - namely, $(1-n) L$. The Collector must receive an additional amount $R^{*}(n)=\max \{0, R-(1-n) L\}$ to satisfy the minimum revenue requirement, $R$. Therefore, the marginal contribution of the Collector to a coalition of $n$ corrupt persons is given by $L(n)=n L-R(n)$. This is illustrated in Figure 1 .

The Shapley value is derived by supposing that the Collector's reward is the average

$$
\begin{aligned}
b(L, R)=E(v(n)) & =\int_{0}^{1} v(n) d n \\
& =(L-R)\left[1-\left(\frac{L-R}{2 L}\right)\right] .
\end{aligned}
$$

overall coalition sizes. This is the area $\mathrm{OBC} 1$ in Figure 1, which yields a total bribe payment of: One way of viewing this in practice is to suppose that tax collection occurs sequentially and that the Collector collects the maximum from each person until the revenue target is met. After that point ( $\overline{\mathrm{n}}$ in Figure 1 ), each Payer individually negotiates with the Collector and shares the gain from collusion, which is the difference between the true liability, $L(i)$, and 0 (what is remitted in the presence of collusion). ${ }^{4}$

This approach is highly stylized, but it does provide a convenient solution to the rentseeking problem with an aggregate budget constraint and several rent seekers. The standard literature on rent-seeking and corruption centers on bargaining between two individuals, without modelling the externality that rent seeking in one bargain has on the surplus available in other bargains. In this model, all agents get to share in potential rents in proportion to what they have to offer. 


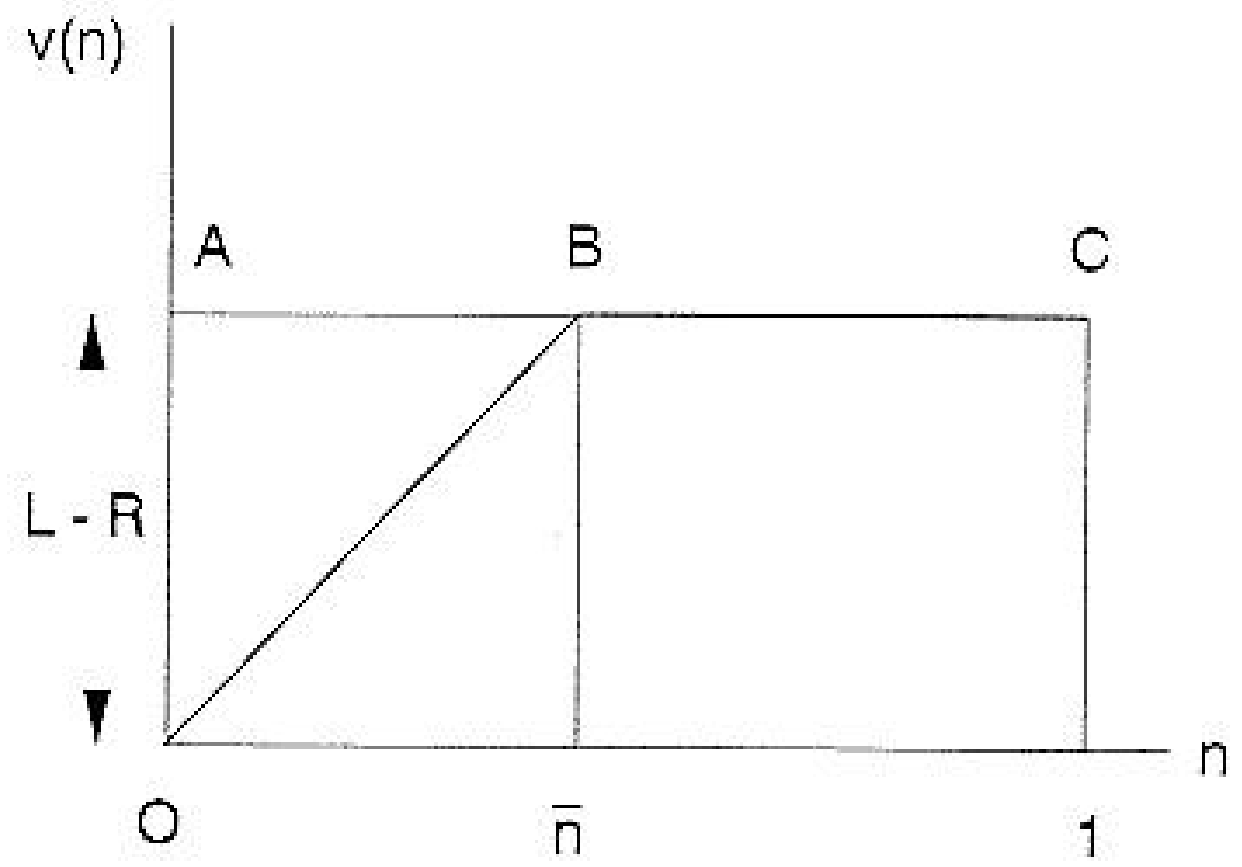

Figure 3. Deturmination of Shapley valuc.

The aggregate surplus accruing to the Payers is the difference between $L-R$ and $b(L, R)$, or the area $O A B$ in Figure 1. While it is possible to derive expressions for the surplus accruing to each Payer at the Shapley value, the only important thing to note here is that unless a Payer has nothing to contribute (in an expected sense) to the corrupt coalition (that is, his or her tax liability is zero, or known to the Minister and hence must be collected and remitted by the Collector) his or her surplus from being corrupt will be positive, and so he or she will choose to be corrupt. Therefore, if there is any scope for corruption, the Payers will choose to take advantage of it. The gains from corruption for the Payers increase with the size of their legal tax liabilities (or the difference between their legal tax liabilities and minimum enforceable tax liabilities).

Now we can ask why the Minister would not simply set $L=R$, thus ensuring the disappearance of all corruption. It is to this issue that we now turn.

\section{Setting incentives for the collector: Wages and bribes as perfect substitutes}

We now focus on the design of incentive systems to ensure that the Collector actually does the job expected by the Minister and that it is done at a reasonable social cost. 
Compensation can take two forms - a standard government-paid wage and bribes.

The central question concerns the circumstances in which corruption is a desirable part of the incentive system. In the simple models of this section, bribes and wages are perfect substitutes, and so, in that sense, corruption is unnecessary. However, in the presence of constraints on government wages, bribe taking can be used as an alternative form of reward for the Collector.

The Minister wishes to raise a certain amount of revenue, $R$. Due to incomplete information concerning the relevant characteristics of Payers, this job must be delegated to a Collector. In return for this, the Collector is paid a wage, $w$. The problem is to ensure that $R$ is actually collected and that this is done at a reasonable social cost.

To monitor the Collector's behavior, and in particular to determine whether the revenue target is actually being met, is costly. Rather than modelling these costs directly, we simply assume that they limit the amount of monitoring that can be undertaken. We treat these costs as exogenous and assume that they permit an audit to be undertaken only once every $\gamma$ time periods. An improvement in the monitoring technology, or a reduction in its costs, would be represented by a decrease in $\gamma$, the time period between audits of the Collector's behavior. ${ }^{5}$

Given the exogenous component of the revenue target, $G$, and the monitoring costs, proxied by $\gamma$, the Minister chooses the Collector's wage, $w$, and a set of tax rules which determine the aggregate legal tax liability, $L$. From the analysis of the aggregate bribe function we see that raising $L$ relative to $R$, in effect, condones greater levels of corruption. But by increasing the Collector's income from bribes, this lowers the size of the official wage which must be paid. In choosing $L$ and $w$ the Minister wants to ensure that the Collector's income is high enough that he will meet the revenue target. (Recall that if the revenue target is not met, the Collector is fired.)

While this is a considerable simplification of the tax collection process, it does capture some essential elements of many such systems in developing countries. The setting of revenue targets which bear little resemblance to the aggregate revenue possibilities of the tax codes is standard practice in many countries. Deal making between taxpayers and tax collectors to reduce tax liabilities is certainly common. One consequence of this is the existence of substantial entry fees to obtain positions in tax collection organizations. Despite such widespread corruption, penalties for corrupt tax collectors are seldom more severe than loss of employment. 
Furthermore, the main reason for prosecution is often not corrupt behavior per se (that is, taking bribes to underestimate tax liabilities) but rather excessive greediness and consequent failure to meet revenue targets. Finally, prosecutions of delinquent taxpayers are generally rare, and penalties are small when they do occur.

The first step in formulating the incentive problem is to look at the Collector's behavior. The Collector's calendar year discount rate is assumed to be $r$, which can be converted into a discount rate per audit year, $\gamma$, of

$$
\delta=e^{-\gamma r}
$$

Thus, if the Collector were to receive a wage, $w$, per calendar year, its present value over an infinite time horizon would be

$$
\sum_{\tau=0}^{\infty} \gamma \delta^{t} w=\frac{\gamma w}{1-\delta}
$$

As long as the Collector continues to be employed, he or she will receive a wage and will be able to collect bribes, $b(L, G+w)$, per audit year. Thus, if the revenue target, $G+w$, is always met, the resulting (infinite) lifetime income will be

$$
\frac{\gamma(w+b(L, G+w))}{1-\delta}
$$

But in any time period the Collector could choose not to meet the target. The implication would be loss of employment as a Collector at the end of that audit year and working in the future elsewhere for some alternative wage, $\bar{w}$. If he or she were to choose not to meet the revenue target, the optimal strategy would be to maximize rents collected that period, which would mean taking the usual bribe of $b(L, R)$, and submitting no revenues to the Minister (that is, take all the money and run).

An efficient compensation package is one that will ensure that the revenue target is always met. The incentive constraint that meets this condition, which we call the take the money and run constraint (TMR), can be written as: 


$$
\frac{\gamma(w+b(L, G+w))}{1-\delta} \geq \gamma(w+b(L, G+w))+\gamma G+\frac{\gamma \delta \bar{w}}{1-\delta}
$$

or

$$
w+b \geq \bar{w}+\left(\frac{1-\delta}{\delta}\right) G .
$$

Observe that we have assumed that the corrupt Collector takes all the government revenue, $\gamma G$. We are assuming implicitly that we are in a repeated relationship, with institutionalized bribery. In such a case, taxpayers have an idea of what is the accepted level of bribery. A corrupt Collector might try to obtain the full liability, $L(i)$, from each person, and therefore take a total amount $L$ and run. In such a case, one might find that taxpayers would not cooperate because they know that the Collector is becoming too greedy and is likely to face severe punishment from the government.

We suppose instead that the excessively greedy collector does not tip his or her hand and collects in the usual manner. One might also expect that the government would recoup some of the stolen money, in which case the total amount that a tax Collector might get would be less than $\gamma G$. It is impossible to predict what this amount might be. Our qualitative results depend only on the assumption that the total amount that a very corrupt Collector would obtain by being excessively greedy is proportional to the amount of tax revenue that the government wishes to collect. Thus we make the simplifying assumption that at the end of $\gamma$ periods the corrupt tax collector considers the possibility of taking the whole pie, $\gamma G$, rather than remitting it to the government.

We define an optimal scheme as one which minimizes the social cost of collecting the revenues $G+w$. This cost is the sum of the wage bill of the Collector and the bribes paid by the Payers, $w+b(L, G+w)$. This cost represents the total amount of resources in the economy that have been diverted from other activities into tax collection. Notice that this is still the correct measure even when the amount paid is in excess of the alternative wage. In that case we know from the rent-seeking literature that individuals divert resources to rent-seeking activities in order to secure these high-paying posts. The salary plus bribe represents the total reallocation of labor to tax collection, inclusive of resources lost to rent-seeking. 
The constraints faced by the Minister are the TMR incentive constraint shown in equation (5) or (6), and the requirement that $L$ be no less than $G+w$ (so that the Collector's task is feasible).

The Minister's problem, therefore, can be stated formally as follows:

$$
\begin{aligned}
& \min _{w, L} C(L, G, w)=w+b(L, G+w) \\
& \text { subject to: } \\
& \quad w+b(L, G+w) \geq \bar{w}+\left(\frac{1-\delta}{\delta}\right) G \\
& \quad L \geq G+w
\end{aligned}
$$

Note that the left hand side of the TMR incentive constraint, (6), is identical to the Minister's cost function, and the right hand side of the constraint is independent of the choice variables $w$ and $L$. Therefore, all pairs, $\left(w^{*}, L^{*}\right)$, that just satisfy the incentive constraint represent identical levels of collection costs.

Examination of the Minister's problem shown in (7) shows that the nature of the solution(s) depends on the properties of the bribe function, $b(L, G+w)$. We digress briefly at this point to examine some of these properties. From the aggregate bribe function (1) it can be shown that

$$
\begin{aligned}
& b_{L}=1-\frac{b}{L}>0,<1 \\
& b_{w}=-\frac{R}{L}<0,>-1,
\end{aligned}
$$

where subscripts refer to derivatives. The first equation in (8) tells us that for a given revenue target, $G+w$, an increase in legal tax liabilities of the Payers permits the Collector to obtain more bribes. But since the increased rents arising from the higher tax liabilities have to be shared with the Payers, the increase in bribes is less than the increase in $L$. From the second of the equations in (8) it is seen that an increase in the Collector's wage reduces the scope for bribes. This is because any increase in $w$, with no change in $G$, requires an increase in the revenue target. But the reduction in bribes is less than the increase in the wage. These results imply the 
following property of the Minister's cost function, $C(L, G, w)$ and the TMR incentive constraint:

$$
\left.L_{w}\right|_{C}=\left.L_{w}\right|_{T M R}=-\left(\frac{1+b_{w}}{b_{L}}\right) .
$$

Since $b_{w}>-1$, and $b_{L}>0$, these contours are negatively sloped in $(L, w)$ space.

Figure 2 illustrates the incentive problem faced by the Minister. The positively sloped line $R=G+w$ shows the boundary between feasible and infeasible tax programs. Points below the line represent infeasible systems - that is, where the revenue target exceeds aggregate tax liabilities. Above the line, $L$ exceeds $R$ and corruption will occur. And points on the line are just feasible, with no opportunities for corruption. The negatively sloped lines are iso-cost contours for the tax-raising function, $C$. With $L>R$, an increase in $L$ will increase bribe payments and hence will require a decrease in $w$ to keep costs constant.

Given the values of $G, \bar{w}$, and $\delta$, one of these iso-cost contours will also represent the TMR incentive constraint, where the Collector is indifferent between continuing to collect $R$ for the Minister and signalling "resignation" by running off with all the tax collections. Suppose that the actual incentive constraint is that labelled $C_{2}$ in Figure 2. Then the solution to the incentive problem is any combination of $w$ and $L$ on or above point $Q$ on that curve. Only at $Q$ will $L=R$ and will there be no corruption. Any of the other solutions will involve some amount of corruption. But they all involve the same total collection costs. Any reduction in bribery costs that would be achieved by reducing $L$ relative to $R$ would be matched by an equal increase in direct wage costs that must be financed by increased "official" tax collections. Official and unofficial wage payments are perfect substitutes.

Corruption is not a necessary part of the efficient tax compensation system, but the nocorruption solution is only one of many. In fact, a wide range of levels of corruption (measured by the magnitude of bribes relative to official tax payments) will be efficient. In other words, in this model corruption can never be excluded as part of an efficient incentive structure. ${ }^{6}$ However, if for any reason the Minister wishes to reduce corruption, the method is straightforward: lower $L$, thus reducing the scope for corruption, while at the same time raise the Collector's wages to compensate for lost earnings and thus inducing continued job performance. This is a standard 
solution that is often offered - to reduce corruption, increase the Collector's wage. An examination of the incentive constraint shows that, to have $b$ equal to zero -that is, to eliminate corruption, the wage must satisfy

$$
w \geq \bar{w}+\left(\frac{1-\delta}{\delta}\right) G
$$

Thus, by paying a sufficiently high wage to the Collector, administrative corruption can be eliminated.

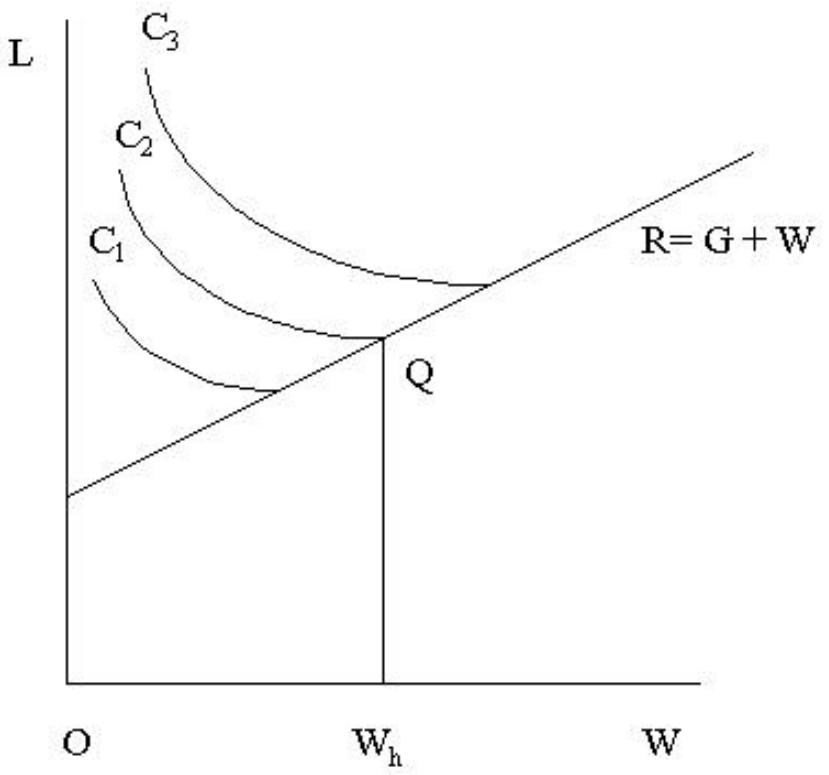

Figure 2. The basic Incentive Problem.

In Figure 2 the minimum wage necessary to eliminate the need for corruption is indicated by $w_{h}$.

From (10) it can also be seen that the greater the ease of monitoring the Collector's behavior - that is, the larger is $\delta$, the lower is the required wage. In terms of Figure 2, improved monitoring shifts the TMR locus closer to the origin, and hence reduces $w_{h}$. The most important underlying cause of corruption is the complex of factors in developing countries that make it difficult to monitor the behavior of the Collector. 
The introduction of penalties more severe than job dismissal as punishment for failing to meet the revenue target would have the same effect. If dismissal were accompanied by a penalty of $P$ (in annuity terms), the zero corruption wage could be written as

$$
w \geq \bar{w}+\left(\frac{1-\delta}{\delta}\right) G-P
$$

Increases in P shift the TMR incentive locus towards the origin.

Equation (10) can also be used to show the proportion of remissions that the Minister would have to permit the Collector to retain in order to prevent any corruption. The minimum retention ratio, $w / G$ can be seen to be $(1-\delta) / \delta$ (assuming an alternative wage of zero). A number of countries operate with a bounty system. ${ }^{7}$ In Grenada, tax collectors receive a 10 percent commission on all collections on delinquent taxpayer accounts. This is apparently sufficient to induce considerable diligence on the part of the collectors. The Commissioner of Inland Revenue in Zambia has recently proposed that his office be freed from normal civil service salary regulations and that all salaries and other collection costs be met out of a straight 10 percent commission on all income tax revenues remitted to the government.

In most developing countries, civil service wages are low - usually less than in private sector jobs requiring similar skills and education. If the Minister is constrained by some need for intragovernment wage parity, then it might well be impossible to offer the Collector a wage that is high enough to satisfy the incentive constraint. The only method available to ensure that tax collection actually occurs in these circumstances will be to raise $\mathrm{L}$ sufficiently above $\mathrm{R}$ to permit bribes to compensate for the low wages. If $\hat{w}$ is the parity-determined wage, then the minimum levels of $L$ and $b$ are given by

$$
w \geq \bar{w}+\left(\frac{1-\delta}{\delta}\right) G-P
$$

A ceiling on the Collector's wages is sufficient to ensure a certain amount of corruption as a solution to the incentive problem. In terms of Figure 2, imagine $\hat{w}$ to the left of $\mathrm{w}_{\mathrm{h}}$. A vertical line drawn from $\hat{w}$ will intersect $\mathrm{C}_{2}$ at a point where $L$ exceeds $R$, and hence there will have to be bribery as part of the efficient compensation package. 
Rather than making $\hat{w}$ exogenous, one could postulate some sort of wage parity between the Collector and the rest of the civil service, so that, in effect, $G$ becomes a positive function of $w$. Then any increase in $w$ to reduce corruption would have the additional cost of raising the size of $G$ necessary to meet core government expenditure needs. This would give rise to a divergence between the TMR constraint and the iso-cost contours, with the latter becoming steeper than the former. Because of the additional cost on the rest of the budget from raising the Collector's wage, this would induce the government to minimize the official wage component of the compensation package and maximize the role of bribes. A level of $w$ sufficiently high to eliminate the need for corruption would be cost-maximizing rather than cost-minimizing.

If corruption is efficient in a particular set of circumstances, the question naturally arises as to the existence of alternative institutional arrangements or other innovations that would lead to efficiency-enhancing reductions in corruption. Two of the most obvious possibilities are (1) delinking $w$ and the rest of civil service wages, and (2) increasing the Collector's discount factor, $\delta$, which is equivalent to reducing the costs and hence increasing the frequency of monitoring. Improvements in auditing technology could lead to efficiency-increasing reductions in both $w$ and $b$. Since this would also decrease the Collector's real income, however, one could magine that he would not be a strong supporter of such innovations. In fact, one would predict that the Collectors would not only be uninterested in finding ways to improve monitoring technology but they would be actively opposed.

As part of a major tax and trade policy reform in the mid-1980s, the Government of Indonesia adopted several measures along these lines. ${ }^{8}$ The most spectacular was to contract out the jobs of inspecting, valuing, and classifying imports for duty collection purposes to a private Swiss surveying company, SGS. Under the new system, all imports to Indonesia in excess of $\$ 5,000$ in value are inspected by this company's agents in the country of export.

In the context of the present model this can be interpreted in several ways. First, this method of contracting out the customs inspection function effectively removed any wage constraints that previously had limited the government's ability to raise the wages of its customs officers. SGS is not restricted by Indonesian government salary scales in setting the wages of its employees throughout the world. Second, as a result of its considerable experience, and the 
immense value of its international reputation, this company has developed and must maintain much more effective and less costly monitoring systems than had been possible in the Indonesian customs service. And third, because of the nature of its business as an international surveying company, SGS has at its immediate disposal enormous amounts of information about goods involved in international trade. This makes its costs of monitoring much smaller than those any single country's customs service. ${ }^{9}$ The fee that is typically charged by SGS for this sort of inspection service is in the range of 1 percent of revenues collected, which is orders of magnitude less than the amounts encountered when governments use a similar incentive system to pay their own tax officials (see discussion at the end of the section 4.1 above.)

A second part of the Indonesian tax reform was the replacement of its complex sales tax structure with a more general credit-type VAT. The drastic simplification of the rate structure (to only one basic rate) and the elimination of many exemptions and other forms of special treatment reduced much of the discretionary authority of the tax officers (raising $\underline{L}$ and reducing monitoring costs in the language of our model). Equally important in this regard was the built-in incentive under the credit-type system for taxpayers to engage in self-monitoring of tax collections, thus drastically reducing monitoring costs of the government.

As would be predicted by our model, the Indonesian customs service and the sales tax office strongly resisted both of these aspects of the tax reform. Similar stories could be told about resistance of tax collectors, in Indonesia and elsewhere, to simplifications in property tax administration, income tax laws, and tariff structures.

A third way to reduce corruption and also the cost of tax collection is to impose more serious penalties than simple job dismissal when corruption is detected. As we have seen, such penalties have the effect of shifting the TMR constraint towards the origin. For any given government wage constraint, a sufficiently high penalty can make the no-corruption wage ( $w_{h}$ in Figure 2) equal to that wage. Why is this not more frequently done? It is to this question that we now turn.

\section{Incentive Systems with Variable Effort by the Collector}

So far we have assumed that the Collector has perfect information about the tax liabilities of the Payers, and the only role for bribe taking is to ensure that the Collector does not abscond 
completely with revenues collected. A much more reasonable assumption is that he can obtain such information only by exerting a certain amount of effort. Since this is costly to the Collector, an efficient reward system should include some incentive to encourage the effort required to determine tax liabilities. By adding this feature to the basic model, ${ }^{10}$ it is possible to demonstrate that (1) allowing a certain amount of corruption is generally more efficient than relying on a pure wage incentive, and (2) a two-level incentive system is called for: some additional penalties, beyond simple dismissal, are required to discourage excessive greed by the Collector. We ague that this model provides a most useful characterization of the principal features of administrative corruption in developing country tax systems.

There are now two possible reasons for the Collector to fail to meet the revenue target, $R$. As before, he might take the money and run. But at the other extreme, he might not exert sufficient effort to collect the required revenue at all. In order to avoid the latter problem, some reward for effort might be helpful. Whatever the reason, we assume, as before, that failure to meet the target results, at least, in the Collector's dismissal.

The amount of effort required to determine a Payer's true tax liability and to collect it is denoted by $f$. Given the revenue target, $R$, and the tax liability rules, $L(i)$, it is possible to calculate, on average, the number of Payers, $n^{*}$, that will have to be investigated to meet the target. The incentive constraint (what we might call the no-shrieking constraint or NSC) becomes:

$$
\frac{\left(w+b-n^{*} f\right)}{1-\delta} \geq w+\frac{\delta \bar{w}}{1-\delta}
$$

The left side is the present value of total income from wages and bribes, net of effort, should the Collector continue to meet his target. If he exerts no effort, he has no opportunity to collect bribes, and fails to meet his target. Thus he is fired at the end of the period, getting $w$ for that one period and thereafter earning the alternative wage, $\cdot \bar{w}$

It is now possible to show that the costs of collection will always be less if the Minister provides some scope for corruption rather than relying strictly on wage payments to reward the Collector. In Figure 3, the iso-cost curves are the same as those drawn in Figure 2. But, whereas 
the TMR constraint in Figure 2 coincided with one of the iso-cost contours, this is not true of the NSC constraint of equation (13). The slope of the NSC can be shown to be

$$
\left.L_{w}\right|_{\text {UEC }}=-\left(\frac{\delta+b_{w}}{b_{L}}\right)
$$

Comparison of this with equation (9), the slope of the iso-cost contours, shows that the NSC constraint is less steep than the iso-cost curves. ${ }^{11}$ The reason is that lure of a bribe makes the

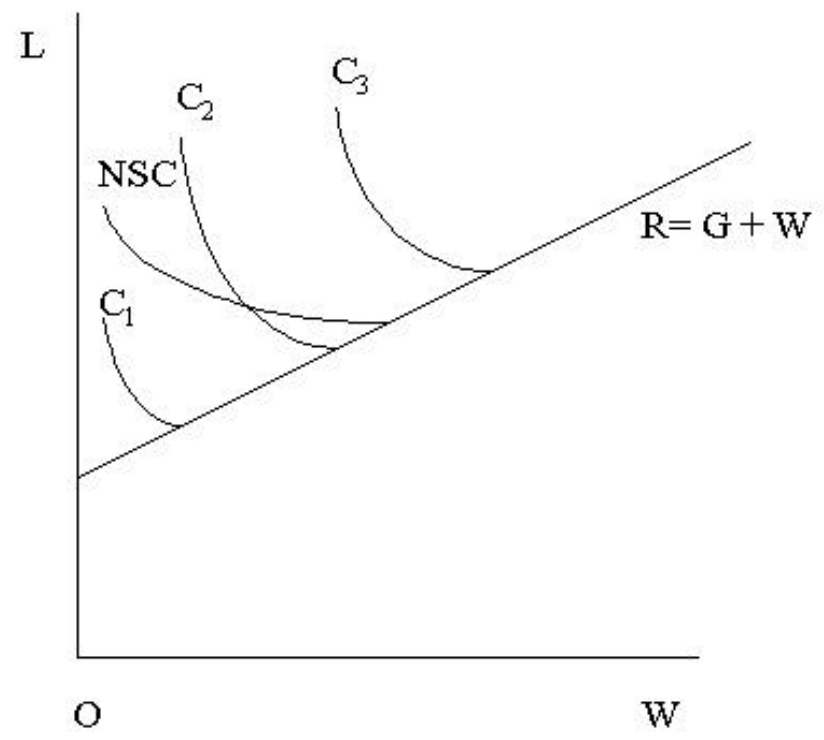

Figure 3. The incentive problem with variable effort.

marginal benefits to the Collector from exerting effort greater than when he is rewarded with a straight wage payment. Compensation in the form of bribes acts like a bounty and hence provides a greater incentive than does a flat wage. In these circumstances the costs of tax collection will be minimized by moving to a position as far to the upper left end of the NSC as possible - that is, by maximizing the share of bribes and minimizing the wage component in the compensation package.

Thus the most efficient way to encourage tax Collector effort in this model is to allow leeway for corruption. The Collector's self-interest in collecting bribes is a much more effective incentive for him or her to determine payers' tax liabilities than is a straight wage payment system. 
Having determined a set of incentives to ensure that the Collector will exert the effort necessary to meet the revenue target, the Minister is still faced with the problem of ensuring that $R$ is actually remitted. That is it must be in the Collector's interest not to take the money and run.

Suppose that $w$ and $L$ are set at levels to solve the shirking problem. Will the threat of dismissal for absconding with state funds be a sufficient deterrent? The answer is clearly no. To see this, we simply rewrite the incentive constraint from the earlier model (equation (6), what we called the take the money and run constraint (TMR)) in a form that incorporates the cost of effort to the Collector. This becomes

$$
\frac{\left(w+b-n^{*} f\right)}{1-\delta} \geq\left(w+b-n^{*} f+G\right)+\frac{\delta \bar{w}}{1-\delta}
$$

(The slope of this constraint in $(L, w)$ space is still given by equation (9).) Comparison of equations (13) and (15) shows immediately that levels of $w$ and $b$ that just satisfy the NSC will certainly not satisfy the TMR constraint. ${ }^{12}$ They are not sufficient to dissuade him or her from taking all of $R$ personally, if the only penalty is loss of employment as Collector.

The situation is illustrated in Figure 4, in which the TMR constraint is everywhere further from the origin than the NSC. Any $(w, L)$ combination on the NSC will be insufficient to satisfy the TMR constraint. One solution to this problem would be to increase $w$ and/or $L$ (and hence $b$ ) sufficiently that the TMR constraint is satisfied. This simply returns us to the first model where, in effect, the NSC is not binding. This would lead to a major increase in the cost of tax collection.

An alternative is to impose stiffer penalties than dismissal in the case of gross malfeasance. Recall (equation (11)) that the imposition of an additional penalty, $P$ lowered the size of wage or amount of leeway for bribes that were necessary to ensure that revenue targets were met. An increase in $P$ has the effect of shifting the TMR constraint towards the origin.

If $P$ is set at a high enough level to shift the TMR constraint in Figure 4 to $\mathrm{TMR}_{1}$, for instance, then the optimal compensation scheme would be $\left(w^{*}, L^{*}\right)$, determined by the intersection of the TMR and NSC curves, or any point above that on the TMR constraint. If the government has chosen a compensation package above this intersection point, then, at no cost, it 
can reduce corruption by tax officials simply by raising wages and lowering $L$, hence moving down and to the right along the TMR curve. But once it reaches the intersection point, further reductions in corruption can be achieved only by moving along the NSC line, and thus moving to higher iso-cost lines and increasing the cost of tax collection. Contrary to the "popular wisdom" confirmed in the earlier model, raising wages in order to reduce corruption is efficient only up to a certain point. $^{13}$

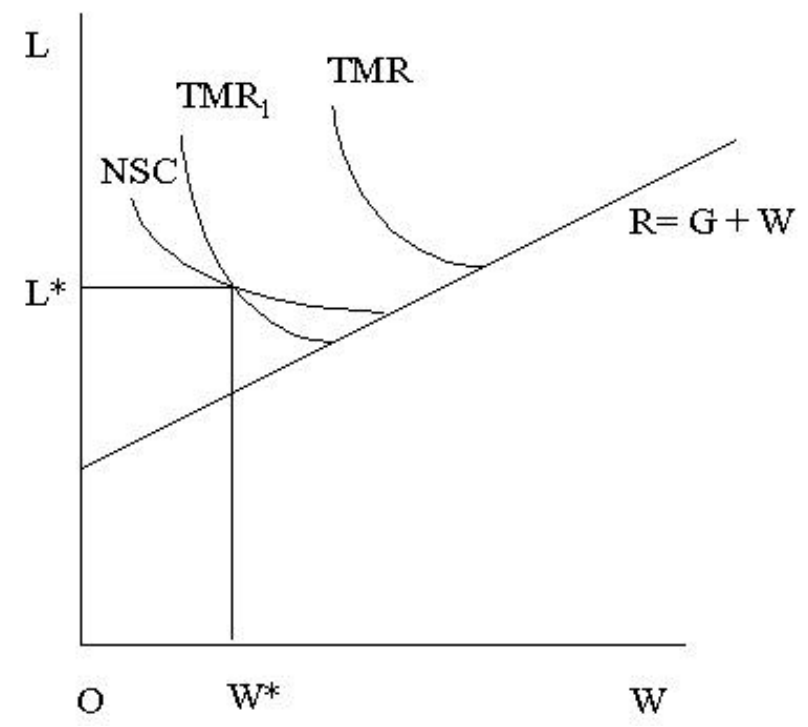

Figure 4. The effect of penalties

Suppose that constraints on civil service wages had forced the government to choose a compensation package to the left of $w^{*}$ along $\mathrm{TMR}_{1}$. Then the Collector would be somewhere above the NSC and hence receiving compensation in excess of his or her supply price. A natural consequence of his is that people would be willing to make side payments to whomever is in a position to offer tax collecting jobs. As observed earlier, this is a common practice in revenue departments in developing countries. What is especially interesting is that the size of the payment they would be willing to make would be larger the further the compensation package is from $\left(w^{*}, L^{*}\right)$. In other words, the size of the payments people would be willing to make for tax collecting jobs will vary inversely with the size of the wage offered for the job.

Use of heavy penalties in instances of gross malfeasance is also standard practice in many developing countries. While considerable amounts of corruption are condoned (and, for reasons we have described, are actually encouraged), excessive greed can be punished, not only by 
dismissal, but by jail sentences and heavy financial penalties. In the framework of this particular model, we could think of the Minister as condoning sufficient corruption to elicit desired effort levels. The penalty for laziness is dismissal. Petty bribe takers are fired not for corruption but for laziness. But if the Collector fails to meet the revenue target not due to laziness but rather because of excessive greed in the form of taking more than a "legitimate" share of the tax revenues, more stringent penalties will be applied.

Thus we see that some corruption might be condoned as a necessary part of tax administration. But it cannot be allowed to go too far. This explains why we often see the apparent anomaly between, on the one hand, large amounts of institutionalized corruption going unpunished, and, on the other, the occasional sensational case of a few tax officials being severely punished for what might seem to be the same sort of activity. The difference is that in the latter case the officials have overstepped the bounds of "normal" levels of corruption and are engaging in activities that threaten the (revenue) integrity of the entire system. The penalties in these cases have to be sufficiently severe to dominate the heavy effect of $G$ on the right side of the TMR constraint.

Several other features of this model are worth highlighting. Consider the effect of a government campaign to crack down on corruption by tax officials. The simple way to portray this would be by an increase in $P$, the penalties imposed on Collectors who are convicted of gross malfeasance. In terms of Figure 4 , an increase in $P$ shifts the TMR curve toward the origin and has no effect on the NSC. The resulting new intersection point of these two curves involves a higher level of $L$ and a lower $w$. Thus, the launching of an anticorruption campaign, in the form of greater penalties for and possibly more publicity surrounding conviction of corrupt officials, might well lead the government to rely more rather than less on "normal" (as opposed to "excessive") bribe taking as a form of compensation for tax collectors. Anticorruption campaigns, while reducing the incidence of gross malfeasance, would have the opposite effect on "petty" bribe taking by tax officials. Of course, if the original equilibrium had not been at the intersection of the TMR and NSC curves, this would not necessarily be the case. Suppose a civil service wage constraint had resulted in an equilibrium at a point along TMR to the northwest of its intersection with NSC. With the NSC nonbinding, as it would be in this case, a leftward shift 
in TMR due to increased penalties would permit the government to reduce corruption (by reducing $L$ ) and continue to maintain the same wage.

The effects of improvements in monitoring technology (or increases in enforcement efforts), represented by increases in $\delta$, are similar to those of increases in $P$ on the TMR constraint. However, changes in monitoring technology also affect the NSC by altering the Collector's rate of discount. First, increases in $\delta$ decrease the difference in the slopes of the NSC and TMR constraint, thus decreasing the comparative advantage of bribes as a bounty system relative to a straight wage. Second, increases in $\delta$ shift the NSC curve towards the origin as long as $w$ exceeds the alternative private sector wage, $w$ faced by dismissed tax collectors. Thus, while improvements in monitoring technology certainly decrease the cost of tax collection, their effects on $w$ and the amount of petty corruption are indeterminate. Of course, if the compensation is constrained, not by the NSC, but rather by civil service wage rules, then it is much more likely that monitoring technology improvements will result in reduced levels of petty corruption.

\section{Summary and Conclusion}

We have constructed a simple framework for modelling administrative corruption and taxation. The two most important analytical issues are (1) the sharing of the rents between the taxpayers and the tax officials and (2) the design of an efficient incentive system for the tax officials. We solve the first problem by utilizing the concept of Shapley value. This gives us a well-defined sharing rule in which rents from the collusion between taxpayers and tax collectors are divided according to the relative powers of the two sets of agents.

The question of incentives for tax collectors is embedded in a model in which the government chooses a wage for tax officials, together with a degree of latitude for corruption based on he slack between aggregate legal tax liabilities and the revenue targets given to the tax officials. These incentives are set at a level that is sufficient to ensure that the tax officials meet the government's revenue target. In the most basic model, bribes and official wages are perfect substitutes. Either form of compensation, or combinations of the two, will ensure that the government's revenue needs will be met in an efficient manner. The total amount of compensation required depends (negatively) on the ability of the government to monitor tax collectors' behavior. 
Two types of considerations turn out to make corruption a necessary part of an efficient solution. The first is the existence of constraints on civil service wages. This could be in the form of a wage ceiling for tax officials, or some sort of wage parity between the tax office and other government departments. Such wage constraints make it impossible for the government to provide sufficient compensation to tax collectors in the form of wages alone. Some condoning of bribe taking is necessary.

The second consideration is the need to induce a certain amount of effort on the part of tax officials in order to determine individual taxpayer liabilities and collect taxes from them. In this case the combination of the threat of dismissal if revenue targets are not met, together with the opportunity to collect bribes as part of the collection process provides the necessary incentive for the tax collectors to go out and raise revenues for the government. Bribes act as a form of unofficial commission for tax collectors.

But having condoned an "acceptable" level of corruption, it is important to ensure that it does not go too far and deprive the government of any revenues at all. The "integrity" of the system must somehow be preserved. The solution to this problem is the imposition of much heavier penalties than simple dismissal in cases of excessive corruption. Hence we observe the apparent condoning of widespread corruption, together with the occasional sensational case in which a few officials receive very high penalties for what is, in quality if not in quantity, exactly the same thing. Petty bribe takers are not generally fired for corruption, but rather for laziness. The only officials who are penalized for corruption are those who try to steal too much. Improvements in the ability of governments to monitor the behavior of their collection officials reduce both the size of the total compensation package required to have them do their job, and also the need for bribes as a part of the compensation package.

While normative in nature, these models provide some interesting predictions about tax design and administrative corruption in developing countries. They help to explain some puzzles about the pervasiveness of administrative corruption and about seemingly peculiar and inconsistent enforcement efforts aimed at reducing it. And some of the obvious policy implications accord with recent tax reform experiences in such countries. 


\section{Acknowledgements}

The stylized facts underlying the models in this paper derive primarily from our own experiences assisting in tax and regulatory reform in a number of developing countries, including Indonesia, Kenya, Malaysia, Peru, Thailand and Zambia. We have benefitted from discussions of these issues with government officials and policy advisers in these and other countries. For obvious reasons we are reluctant to provide precise citations for many of the examples of corruption described in this paper. Several people have helped us with general discussions on administrative corruption in developing country tax systems and with comments on earlier versions of this paper. In this regard, we would like to acknowledge the insights and suggestions of Robin Boadway, Glenn Jenkins, Hervé Moulin, Ammar Siamwalla, Dan Usher, Ed West, Gordon Cox, Wil Krause, and Jim Owens. These last three were formerly with British Customs, Canada Customs and the US Internal Revenue Service, respectively, and all three now work as tax and customs advisors in developing countries. Two referees and the Editor, Mick Keen, provided very useful comments and suggestions. Financial support from FCAR (Québec) and SSHRCC (Canada) is also gratefully acknowledged.

\section{Notes}

1. In an important volume representing more or less the state of the art on the theory of taxation in developing countries (Newbery and Stern, 1987), only two of almost 700 pages (pp. 200-202) are devoted to this problem. The editors refer to this an important omission and an area ripe for future research (pp. 651-652). Besley and McLaren (1993) is the only paper of which we are aware that models administrative corruption in tax systems. In other contexts, such as government contracting, Rose-Ackerman (1978, 1986) provides some interesting analysis of the economics of administrative corruption.

2. These results are reminiscent of those of Becker and Stigler (1974), in which they discuss the roles of high wages and incentive payments (bounties) as alternative means of compensating law enforcers. The use of bounties to reward tax collectors could be thought of as a form "tax farming" as a means of revenue raising (see Adam Smith, 1776, pp. 853-855.)

3. This behavior might appear to be redundant or inconsistent. In developing countries, however, the setting of revenue targets for tax officials is central to the tax collection process. In Indonesia, for instance, the Director General of Taxes, based on overall revenue requirements set by the Minister of Finance, sets revenue targets for each of the major tax divisions (customs, excise, personal and corporate income, and so on). The Directors of these divisions break these down into targets for regional and district offices. Each of these revenue targets is less than legal tax liabilities for the tax or region. As will be seen, our model provides an explanation of this phenomenon in terms of the incentives for tax collectors.

4. See Gul (1989) for a discussion of explicit bargaining games that implement the Shapley value.

5. $\gamma$ might well depend on the nature of the tax liability function, $L(i)$, on the general level of economic development, or on some other factors. We do not attempt to incorporate such relationships into the model in this paper. However, observations based on the experiences of some developing countries are offered later below. 
6. A unique, no-corruption solution - with an iso-cost contour starting at the vertical intercept of the $R$ line - does not exist. The reason is that this would imply zero collection costs, and hence also zero opportunity costs, for the collector. Thus all solutions are multiple solutions, with no corruption only one particular possibility.

7. Note however that a bounty system differs from a straight wage system of the type we have discussed to this point. As we shall see in a later section, it is the fact that bribes are more similar to a bounty system that gives some comparative advantage to their use as part of the compensation system when monitoring is difficult.

8. For more details on these reforms see Gillis (1985) and Barichello and Flatters (1990). The former deals primarily with tax policies and the latter with trade regulation.

9. See Flatters and Jenkins (1991) for a discussion of the informational advantages of using a preshipment inspection system, such as that being used by SGS in Indonesia, in developing countries.

10. For the purpose of analytical simplicity we drop from the model the wage effects and constraints discussed in the immediately preceding subsection.

11. In fact it is possible for the NSC locus to become positively sloped. This would happen if the absolute value of $b_{w}$ were larger than $\delta$. This would mean that the direct benefits to the collector of a wage increase was outweighed by the indirect negative effect of the wage increase on the scope for bribe taking, due to the need for the government to increase the revenue target to meet the higher wage bill. We ignore this unlikely case in the following discussion.

12. This assumes, quite reasonably, that $G+b>n * f$.

13. Moving to the opposite end of the TMR constraint, to the point where it intersects the vertical axis and wages are zero could be thought of as a pure tax farming solution. This still leaves the Minister with the problem of ensuring that the tax farmer actually remits the payments agreed to in return for the franchise. The least cost tax farming solution would be achieved by setting $P$ at a level such that the TMR constraint intersects the vertical axis at the same point as the NSC curve. $L$ would be set at exactly that level. A lower $P$ or higher $L$ would yield unnecessary rents for the tax farmer; and higher $P$ or lower $L$ would provide an insufficient incentive for the tax farmer to undertake the task.

\section{References}

Allingham, Michael G., and Agnar Sandmo. (1972). "Income Tax Evasion: A Theoretical Analysis." Journal of Public Economics, 1, 323-338.

Barichello, Richard, and Frank Flatters. (1990) "Trade Policy Reform in Indonesia." In Dwight Perkins and Michael Roemer (eds.), Systems Reform in Developing Countries, Cambridge, MA: Harvard University Press.

Basu, Kaushik, Sudipto Bhattacharya, and Ajit Mishra. (1992). "Notes on Bribery and the Control of Corruption." Journal of Public Economics 48, 349-359.

Becker, Gary, and George Stigler. (1974). "Law Enforcement, Malfeasance, and Compensation of 
Enforcers." Journal of Legal Studies, 3, 1-18.

Besley, Timothy, and John McLaren. (1993). "Taxes and Bribery: The Role of Wage Incentives." Economic Journal 103, 119-141.

Cowell, F.A. (1990). Cheating the Government: The Economics of Evasion, Cambridge, MA: MIT Press.

Cremer, H., M. Marchand, and P. Pestieau. (1988). "Evading, Auditing and Taxing: The EquityCompliance Tradeoff." Mimeo.

Flatters, Frank, and Glenn Jenkins. (1991). "Fiscal and Institutional Innovations for Export Expansion in Developing Countries." Paper presented at International Tax Program Conference on Directions of Tax Reform in Emerging Economies, Harvard University Law School, November.

Gillis, Malcolm. (1985). "Micro and Macro Economics of Tax Reform: Indonesia." Journal of Development Economics, 19, 221-254.

Graetz, Michael J., Jennifer F. Reinganum, and Louis T. Wilde. (1986). "The Tax Compliance Game: Toward an Interactive Theory of Law Enforcement." Journal of Law, Economics and Organization 2(1), 1-32.

Gul, Faruk. (1989). "Bargaining Foundations of the Shapley Value." Econometrica 57(1), 81-95.

Moulin, Herve. (1988). Axioms of Cooperative Decision Making, Cambridge, MA: Cambridge University Press

Newbery, David, and Nicholas Stern (eds.). (1987). The Theory of Taxation for Developing Countries, Oxford: Oxford University Press, for the World Bank.

Ordeshook, Peter C. (1986). Game Theory and Political Theory: An Introduction. Cambridge: Cambridge University Press.

Reinganum, Jennifer, and Louis T. Wilde. (1985). "Income Tax Compliance in a PrincipalAgent Framework." Journal of Public Economics 26, 1-18.

Rose-Ackerman, Susan. (1978). Corruption: A Study in Political Economy. New York: Academic Press.

Rose-Ackerman, Susan. (1986). "Reforming Public Bureaucracy through Economic Incentives?" Journal of Law, Economics and Organization.2(1), 131-161.

Smith, Adam. (1776). An Enquiry into the Nature and Causes of the Wealth of Nations. New York, NY: Random House, Modern Library Edition.

Toma, Eugenia Froedge, and Mark Toma. (1992). "Tax Collection With Agency Costs: Private Contracting or Government Bureaucrats?" Economica 59, 107-120.

Usher, Dan. (1986). "Tax Evasion and the Marginal Cost of Public Funds." Economic Inquiry 24, 563-586.

Yitzhati, S. (1987). "On the Excess Burden of Tax Evasion." Public Finance Quarterly, 123-137. 